\title{
Production pressures among anaesthesiologists in Singapore
}

Jia Xin $\underline{\text { Chai }}^{1,2}$, MBBS, MMed, Shin Yuet Chong $^{2}$, MBBS, MMed

INTRODUCTION Production pressure is the pressure on personnel to prioritise production ahead of safety. We assessed the prevalence of production pressures among anaesthesiologists in Singapore.

METHODS A random online survey was conducted among local anaesthesiologists. Questions were asked about attitudes to production pressures in the work environment, occurrence of situations involving unsafe actions, and rating of the intensity of external and internal sources of pressure.

RESULTS Demographically, our respondents were largely similar to all anaesthesiologists in Singapore and were fairly distributed across various tertiary hospitals. Nearly half $(44.5 \%)$ had witnessed production pressures, with a colleague pressured to conduct anaesthesia in an unsafe manner. Such events included pressure from surgeons to proceed for elective surgery in patients without adequate optimisation, pressure to employ anaesthetic techniques that surgeons wanted, having to source for operating rooms to finish the surgeon's list, and being misled regarding surgical time. Over half $(52.3 \%)$ made errors in clinical judgement due to excess workload. A heavy elective list workload was significantly associated with proceeding with patients despite lack of appropriate support, making changes to practices to avoid delaying the start of surgery and sourcing for operating rooms to finish the surgeon's list $(p<0.05)$, and being pressured to proceed with patients that the anaesthesiologist would otherwise have cancelled $(p<0.01)$. The need to avoid delaying the start of surgery and reduce turnover time between patients were the top-ranked internal and external pressures, respectively. CONCLUSION Production pressure is prevalent among anaesthesiologists in Singapore and is correlated with a heavy workload.

Keywords: patient safety, production pressure, professional practice

\section{INTRODUCTION}

'Production pressure' is a term used to describe the "overt or covert pressures and incentives on personnel to place production, not safety, as their primary priority'. (1) In hospitals, there is increasing pressure in various departments to ensure the production and generation of results to meet key performance indicators. The emphasis on production may pose a threat to patient safety by leading to errors that may compromise patient safety. Reason's Swiss cheese model is an oft-quoted model that explains how defence barriers can be individually surpassed, such that an accidental trajectory through all barriers can ultimately lead to a negative outcome. This model is often used during hospital quality control rounds when evaluating incidents with adverse outcomes for systemic errors. Production pressure applied at any level of the model can amplify the risk and rate of occurrence of error. ${ }^{(2)}$ It accelerates the breakdown of individual barriers, which increases the probability of adverse outcomes. However, it has not been extensively assessed as an important cause of systemic error.

The operating room is a highly structured entity in the hospital, where various systems and checks exist to reduce systemic error and ensure patient safety. Anaesthesia, which is a discipline often compared to systems such as airline safety, involves complex decisions that can have an immediate impact on patient life. Every detail in a general anaesthetic procedure, from induction to recovery, has to be picked up and acted upon immediately, similar to any deviation from the norm in a commercial flight. Nonetheless, production pressures that anaesthesiologists are subject to exist in internal (e.g. pressures placed on oneself) and external (e.g. pressure from surgeons, administration or colleagues) forms. This was the focus of a 1994 study on anaesthesiologists from California, United States, ${ }^{(1)}$ but to our knowledge, has not been studied locally.

Our study aimed to evaluate the prevalence and degree of production pressures among anaesthesiologists in Singapore. Such knowledge could help to increase awareness and improve the welfare of anaesthesiologists in Singapore, with the primary goals being better patient safety and improved patient outcomes.

\section{METHODS}

We referred to the original survey on production pressure in the 1994 study by Gaba et al, (1) which was a 13-page survey that collected demographic data and attitudes of respondents to production pressures. We contacted the original authors via email correspondence and obtained a copy of the original survey and their permission to adapt the survey for local use. The result was a four-page survey that had six questions on demographic data, 23 statements on attitudes to the work environment with responses on a 5-point Likert scale, and 12 statements on respondents' ratings of the intensity of external and internal sources of production pressures. The survey was in a user-friendly form on SurveyMonkey, which was easily accessible via a website address.

${ }^{1}$ SingHealth Anaesthesiology Residency Programme, ${ }^{2}$ Department of Anaesthesiology, Singapore General Hospital, Singapore

Correspondence: Dr Chai Jia Xin, Resident, SingHealth Anaesthesiology Residency Programme, Department of Anaesthesiology, Singapore General Hospital, Outram Road, Singapore 169608. jiaxin.chai@mohh.com.sg 
Two types of scales were used in the survey. For attitudes on production pressures, the respondents were asked if they agreed or disagreed with a series of statements on a 5-point Likert scale. For ratings on intensity of production pressures, a horizontal numerical scale from 1 to 5 was used. In addition, we had a freetext section for respondents to elaborate on incidents in which they witnessed various forms of production pressures, without the use of any identifiers. The full questionnaire is attached in the Appendix. All responses were anonymous. An application was made to SingHealth Centralised Institutional Review Board for exemption, which was granted (CIRB Ref no. 2015/2209).

Specialist anaesthesiologists in Singapore were contacted with the assistance of secretaries in the restructured hospitals and the Singapore Society of Anaesthesiologists. An email was sent to the secretaries to be disseminated to associate consultants, consultants and senior consultants in their respective departments. An email requesting for a response to the survey was sent in March 2015, with a repeat email in April 2015.

Analyses were performed using IBM SPSS Statistics version 20 (IBM Corp, Armonk, NY, USA). Demographic data was summarised by tabulation for nominal data and in graphical form for interval data. The data from Likert scales and horizontal numerical scales was presented as tables.

With reference to the original 1994 study, the statements that indicated the presence of production pressures were chosen and Kendall's tau non-parametric correlation coefficient analysis was applied to determine correlations, if any, between: (a) work hours and experiences with fatigue; (b) workload and external pressures from surgeons; and (c) workload and external pressures from administrators. Our aim was to determine the correlating variables and how they lead to manifestations of production pressures for participating anaesthesiologists.

\section{RESULTS}

The demographics and response rate of our respondent population are shown in Table I and Fig. 1, respectively. There was a fair distribution of respondents across all hospitals - Changi General Hospital (10.9\%), Khoo Teck Puat Hospital (7.8\%), KK Women's and Children's Hospital (12.5\%), Ng Teng Fong General Hospital (12.5\%), National University Hospital (14.1\%), Singapore General Hospital (26.6\%) and Tan Tock Seng Hospital (15.6\%). The response rate from each hospital department is illustrated in Fig. 1. There were no responses from private practitioners. A total of 70 responses were received for the pilot study, with six incomplete responses that were excluded from analysis. Finally, 64 respondents were included in the study.

A majority $(82.6 \%)$ of respondents worked in operating theatre suites with more than 11 operating rooms, while $49.3 \%$ of respondents worked in operating theatre suites with more than 20 operating rooms. On average, $52.2 \%$ of respondents attended to $2-4$ cases on a typical workday. About $43.3 \%$ of respondents said $26 \%-50 \%$ of their cases were outpatients on a typical workday theatre list. On average, most $(65.2 \%)$ of the respondents worked 41-60 hours in a week. A majority (58.0\%) of respondents had been in anaesthetic practice for more than 15 years.
Table I. Demographics of participating anaesthesiologists $(n=64)$.

\begin{tabular}{|ll|}
\hline Variable & $\begin{array}{l}\% \text { of } \\
\text { respondents }\end{array}$ \\
\hline $\begin{array}{l}\text { No. of operating rooms in the operating } \\
\text { theatre suite }\end{array}$ \\
\hline $1-3$ & \\
\hline $4-6$ & 0 \\
\hline $7-10$ & 7.3 \\
\hline $11-20$ & 10.1 \\
\hline$>20$ & 33.3 \\
\hline Mean no. of cases in a typical workday & 49.3 \\
\hline $0-1$ & \\
\hline $2-4$ & 1.4 \\
\hline $5-7$ & 52.2 \\
\hline$>7$ & 37.7 \\
\hline Outpatients in the list on a typical workday (\%) & 8.7 \\
\hline $1-25$ & 26.9 \\
\hline $26-50$ & 43.3 \\
\hline $51-75$ & 17.9 \\
\hline $76-100$ & 11.9 \\
\hline Duration of work in a week (hr) \\
\hline $0-20$ & 1.5 \\
\hline $21-40$ & 17.4 \\
\hline $41-60$ & 65.2 \\
\hline $61-80$ & 10.1 \\
\hline$>80$ & 5.8 \\
\hline Time in anaesthetic practice (yr) & 21.8 \\
\hline$<5$ & 2.9 \\
\hline $6-10$ & 13.0 \\
\hline $11-15$ & 20.3 \\
\hline $16-20$ & \\
\hline $21-25$ & \\
\hline$>25$ & \\
\hline
\end{tabular}

The attitudes of respondents to various sources of pressure in their work environment are presented in Table II. Responses on fatigue as a source of internal pressure indicated that $41.5 \%$ of respondents felt that their elective list workload was heavy (Item 7.1), while $41.6 \%$ felt that their call workload was heavy (Item 7.2). More than half (52.3\%) of the respondents said they had made errors in clinical judgement during a case and attributed this to their excess workload (Item 7.3). A correlation analysis between workload and fatigue using Kendall's tau non-parametric correlation coefficient analysis found that the number of work hours in a week, size of the operating theatre suite and average number of cases in a day were significantly correlated with a heavy elective list workload ( $p<0.05$; Table III). In addition, a heavy elective list workload was significantly correlated with a heavy call workload $(p<0.05)$. Both heavy elective list workload and heavy call workload had significant correlations with having made errors in clinical judgement that were attributable to excess workload during a case $(p<0.05)$.

Regarding attitudes towards external pressures from surgeons (Table II), we found that $47.7 \%$ of respondents felt they had 


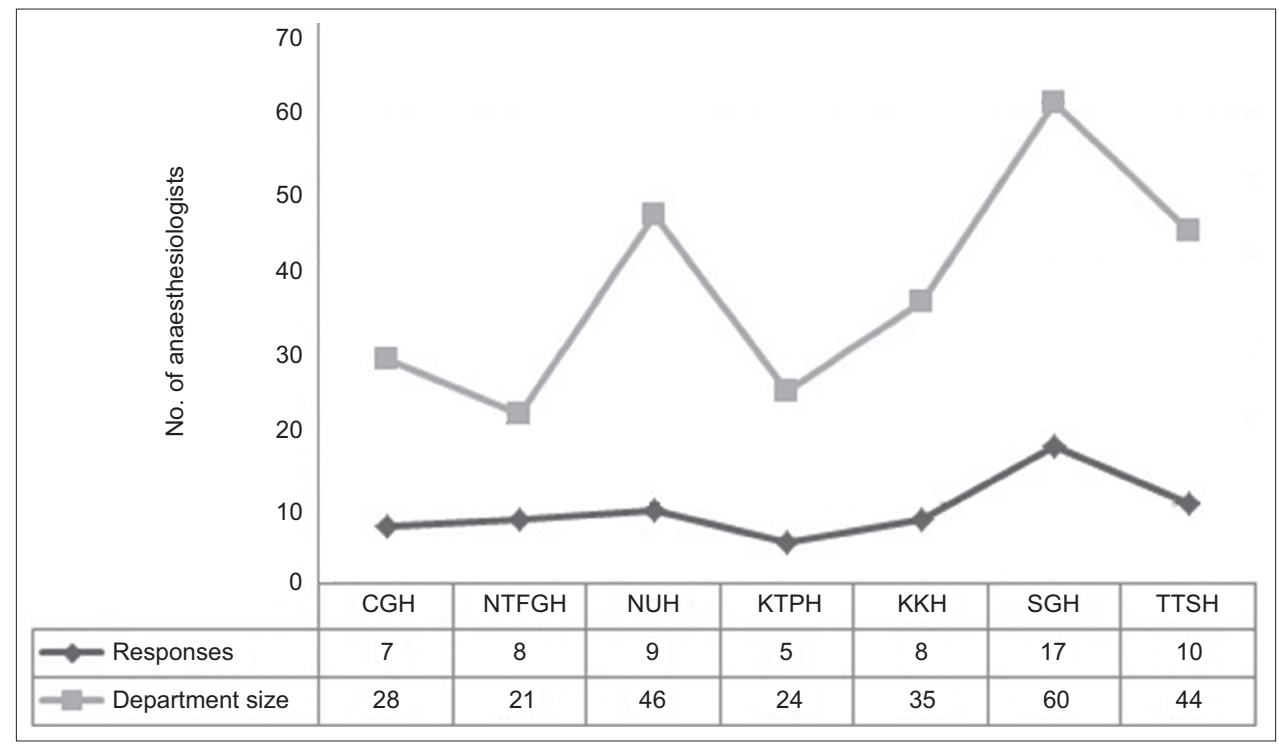

Fig. 1 Chart shows relationship between response rate and hospital department size for anaesthesiologists who completed the survey (data as of 30 April 2015). CGH: Changi General Hospital; KKH: KK Women's and Children's Hospital; KTPH: Khoo Teck Puat Hospital; NTFGH: Ng Teng Fong General Hospital; NUH: National University Hospital; SGH: Singapore General Hospital; TTSH: Tan Tock Seng Hospital

Table II. Respondents' attitudes to the work environment.

\begin{tabular}{|c|c|c|c|c|c|}
\hline \multirow[t]{2}{*}{ Variable } & \multicolumn{5}{|c|}{$\%$ of respondents } \\
\hline & Strongly disagree & Disagree & Neutral & Agree & Strongly agree \\
\hline \multicolumn{6}{|c|}{ Internal pressure: fatigue } \\
\hline Item $7.1^{*}$ & 1.6 & 24.6 & 32.3 & 29.2 & 12.3 \\
\hline Item $7.2^{*}$ & 1.5 & 24.6 & 32.3 & 30.8 & 10.8 \\
\hline Item $7.3^{*}$ & 7.7 & 16.9 & 23.1 & 44.6 & 7.7 \\
\hline Item $7.8^{*}$ & 1.5 & 27.7 & 32.3 & 30.8 & 7.7 \\
\hline \multicolumn{6}{|c|}{ External pressure: surgeons } \\
\hline Item $7.12^{*}$ & 7.7 & 29.2 & 15.4 & 36.9 & 10.8 \\
\hline Item $8.7^{\dagger}$ & 3.2 & 25.4 & 19.1 & 44.4 & 7.9 \\
\hline Item $7.4^{*}$ & 49.2 & 41.5 & 6.2 & 3.1 & 0 \\
\hline Item $8.8^{+}$ & 1.6 & 7.9 & 17.5 & 50.8 & 22.2 \\
\hline Item $8.6^{+}$ & 4.7 & 3.2 & 28.6 & 50.8 & 12.7 \\
\hline \multicolumn{6}{|c|}{ External pressure: administrative, facilities } \\
\hline Item $7.6^{*}$ & 3.1 & 26.2 & 13.8 & 36.9 & 20.0 \\
\hline Item $8.1^{+}$ & 1.6 & 34.9 & 15.9 & 41.3 & 6.3 \\
\hline \multicolumn{6}{|c|}{ Protective factors } \\
\hline Item $8.2^{+}$ & 0 & 9.5 & 15.9 & 61.9 & 12.7 \\
\hline Item $7.10^{*}$ & 0 & 16.9 & 10.8 & 49.2 & 23.1 \\
\hline Item $8.4^{+}$ & 4.8 & 30.1 & 33.3 & 30.2 & 1.6 \\
\hline \multicolumn{6}{|c|}{ On production pressures } \\
\hline Item $8.10^{+}$ & 1.6 & 3.2 & 14.3 & 47.6 & 33.3 \\
\hline Item $8.11^{+}$ & 7.9 & 9.5 & 38.1 & 31.8 & 12.7 \\
\hline
\end{tabular}

Refer to Appendix *Section 7 'On work environment and situation' and +Section 8 'On work environment and situation (continued)' for full statements.

proceeded with cases they would otherwise have cancelled except for the fact that the surgeon or patient wanted to go ahead with the procedure (Item 7.12). 52.3\% of respondents had made changes to their practice in order to facilitate the start of surgery, e.g. choosing general over regional anaesthesia even though regional anaesthesia would have been their preferred technique (Item 8.7). An overwhelming $90.7 \%$ of respondents disagreed with the statement that there had never been a need or reason to cancel a case from the surgical schedule (Item 7.4). $73.0 \%$ of respondents reported having to source for operating rooms to finish the surgeon's list (Item 8.8).

The correlation analysis between workload and external pressures (Table IV) found that a heavy elective list workload (Item 7.1) was significantly associated with proceeding with cases despite lack of appropriate support (Item 8.1; $p<0.05$ ), making changes to the practice to facilitate the start of surgery (Item 8.7; 
$p<0.05)$, sourcing for operating rooms to finish the surgeon's list (Item 8.8; $\mathrm{p}<0.05$ ) and being pressured into proceeding with cases they might otherwise have cancelled (Item 7.12; $p<0.01$ ).

On administrative pressures, $56.9 \%$ of respondents felt that there was administrative pressure to keep time between cases to a minimum (Item 7.6). $47.6 \%$ of respondents had proceeded with cases despite lack of appropriate support, such as technical support and intensive care beds (Item 8.1). Responses to queries on protective factors revealed that a majority $(74.6 \%)$ of respondents had refused to do a case because the risks outweighed the benefits (Item 8.2 ). $72.3 \%$ of respondents had cancelled cases in which the patient had not undergone adequate preoperative evaluation (Item 7.10 ). Only $31.8 \%$ of respondents had cancelled cases for fear of litigation if they had proceeded (Item 8.4).

Table III. Correlation between workload and experiences with fatigue based on Kendall's tau non-parametric correlation coefficient analysis.

\begin{tabular}{|c|c|c|c|}
\hline \multirow[t]{3}{*}{ Variable } & \multicolumn{3}{|c|}{ Statement } \\
\hline & Item & Item & Item \\
\hline & 7.1 & 7.2 & 7.3 \\
\hline \multicolumn{4}{|c|}{ No. of work hours in a week } \\
\hline Correlation coefficient & $0.308^{*}$ & 0.177 & $0.285^{*}$ \\
\hline Significance (2-tailed) & 0.005 & 0.108 & 0.010 \\
\hline \multicolumn{4}{|l|}{ No. of operating rooms } \\
\hline Correlation coefficient & $0.337^{*}$ & $0.225^{+}$ & -0.017 \\
\hline Significance (2-tailed) & 0.002 & 0.040 & 0.876 \\
\hline \multicolumn{4}{|c|}{ Average no. of cases in a day } \\
\hline Correlation coefficient & $0.270^{+}$ & 0.007 & 0.044 \\
\hline Significance (2-tailed) & 0.015 & 0.947 & 0.692 \\
\hline \multicolumn{4}{|c|}{ Heavy elective list workload } \\
\hline Correlation coefficient & 1.000 & $0.405^{*}$ & $0.215^{+}$ \\
\hline Significance (2-tailed) & - & $<0.001$ & 0.040 \\
\hline \multicolumn{4}{|l|}{ Heavy call workload } \\
\hline Correlation coefficient & $0.405^{*}$ & 1.000 & $0.208^{+}$ \\
\hline Significance (2-tailed) & $<0.001$ & - & 0.048 \\
\hline
\end{tabular}

Refer to Appendix Section 7 'On work environment and situation' for full statements. ${ }^{*} p<0.01$ and $+p<0.05$ were statistically significant.
The respondents were asked to rank the various sources of internal (Table V) and external (Table VI) pressures. The two most highly ranked factors among sources of internal pressures were the need to avoid delaying the start of surgery (Item 9.2; average rating 3.56) and need to avoid litigation (Item 9.6; average rating 3.10). For external pressures, the need to reduce turnover time between cases (Item 10.4; average rating 3.31) and proceeding with cases rather than cancelling (Item 10.1; average rating 3.13) were the top two factors.

In the real-life work environment, $80.9 \%$ of respondents agreed that production pressures had a negative impact on patient safety (Item 8.10). About $44.5 \%$ of respondents had witnessed a colleague pressured into conducting anaesthesia in an unsafe manner given the level of urgency of the situation (Item 8.11). Respondents were asked to provide non-identifying descriptions of such events and 16 responses were received. The responses were for external pressures and could be broadly divided into the following categories: pressure from surgeons; pressure to proceed despite inadequate preoperative evaluation; administrative external pressures related to insufficient resources; and pressure to proceed despite fatigue.

Examples of external pressures from surgeons included 'pressure to employ anaesthesia technique that surgeon wanted, such as awake fibreoptic intubation for a patient with stridor from subglottic stenosis when a more senior anaesthesia colleague had decided that awake tracheostomy is safer'; 'surgeon using seniority to boss (around) junior anaesthetists to start complex cases with junior surgeons'; 'pressure by senior surgeons who refuse to wait for a block to work'; 'eye surgeons insisting on more sedation instead of repeating eye block or giving more eye drops'; and 'monitored anaesthesia care being rushed to be converted to general anaesthesia'.

Examples of pressure to proceed despite inadequate preoperative evaluation included 'patient with uncontrolled hypertension proceeded for general anaesthesia for colorectal operation, ended up with afterload failure in the intensive care unit'; 'inadequate fasting less than four hours but proceeded for shared

Table IV. Correlation between workload and external pressures based on Kendall's tau non-parametric correlation coefficient analysis.

\begin{tabular}{|c|c|c|c|c|}
\hline \multirow[t]{2}{*}{ Variable } & \multicolumn{4}{|c|}{ Statement } \\
\hline & Item 7.12* & Item $8.1^{+}$ & Item $8.7^{+}$ & Item $\mathbf{8 . 8}^{+}$ \\
\hline \multicolumn{5}{|l|}{ Item 7.1* } \\
\hline Correlation coefficient & $0.292^{\ddagger}$ & $0.255^{\S}$ & $0.267 \S$ & $0.274 \S$ \\
\hline Significance (2-tailed) & 0.005 & 0.019 & 0.013 & 0.011 \\
\hline \multicolumn{5}{|l|}{ Item 7.12* } \\
\hline Correlation coefficient & 1.000 & $0.469^{*}$ & $0.322^{\neq}$ & $0.411^{*}$ \\
\hline Significance (2-tailed) & - & $<0.001$ & 0.003 & $<0.001$ \\
\hline \multicolumn{5}{|l|}{ Item $8.1^{+}$} \\
\hline Correlation coefficient & $0.469^{*}$ & 1.000 & $0.360^{\ddagger}$ & $0.323^{*}$ \\
\hline Significance (2-tailed) & $<0.001$ & - & 0.001 & 0.003 \\
\hline \multicolumn{5}{|l|}{ Item $8.7^{+}$} \\
\hline Correlation coefficient & $0.322^{*}$ & $0.360^{\neq}$ & 1.000 & $0.229 \S$ \\
\hline Significance (2-tailed) & 0.003 & 0.001 & - & 0.036 \\
\hline
\end{tabular}

Refer to Appendix *Section 7 'On work environment and situation' and +Section 8 'On work environment and situation (continued)' for full statements. $\neq \mathrm{p}<0.01$ and $\S p<0.05$ were statistically significant. 
Table V. Rating of intensity of internal pressures (i.e. pressures that anaesthesiologists put on themselves).

\begin{tabular}{|c|c|c|c|c|c|c|}
\hline \multirow[t]{2}{*}{ Variable } & \multicolumn{5}{|c|}{ Pressure rating (\% of respondents) } & \multirow{2}{*}{$\begin{array}{l}\text { Average } \\
\text { rating }\end{array}$} \\
\hline & 1 (no pressure) & 2 & 3 & 4 & 5 (intense pressure) & \\
\hline Item 9.1 & 11.3 & 21.0 & 37.1 & 27.4 & 3.2 & 2.90 \\
\hline Item 9.2 & 3.2 & 4.8 & 32.3 & 51.6 & 8.1 & 3.56 \\
\hline Item 9.3 & 25.8 & 24.2 & 32.3 & 11.3 & 6.4 & 2.48 \\
\hline Item 9.4 & 22.6 & 33.9 & 27.4 & 9.7 & 6.4 & 2.44 \\
\hline Item 9.5 & 25.8 & 19.4 & 35.5 & 14.5 & 4.8 & 2.53 \\
\hline Item 9.6 & 12.9 & 17.7 & 30.7 & 24.2 & 14.5 & 3.10 \\
\hline
\end{tabular}

Refer to Appendix Section 9 'Please rate on a scale of 1-5 (1: no pressure; 5 : intense pressure) how much you feel these internal pressures (i.e. pressures that you put on yourself) in your environment' for full statements.

Table VI. Rating of intensity of external pressures (i.e. pressures someone else, e.g. surgeon, administrator, colleague, puts on anaesthesiologists).

\begin{tabular}{|c|c|c|c|c|c|c|}
\hline \multirow[t]{2}{*}{ Variable } & \multicolumn{5}{|c|}{ Pressure rating (\% of respondents) } & \multirow{2}{*}{$\begin{array}{l}\text { Average } \\
\text { rating }\end{array}$} \\
\hline & 1 (no pressure) & 2 & 3 & 4 & 5 (intense pressure) & \\
\hline Item 10.1 & 8.1 & 22.6 & 27.4 & 32.2 & 9.7 & 3.13 \\
\hline Item 10.2 & 22.6 & 27.4 & 21.0 & 24.2 & 4.8 & 2.61 \\
\hline Item 10.3 & 9.7 & 24.2 & 25.8 & 35.5 & 4.8 & 3.02 \\
\hline Item 10.4 & 9.7 & 12.9 & 27.4 & 37.1 & 12.9 & 3.31 \\
\hline Item 10.6 & 24.2 & 27.4 & 24.2 & 16.1 & 8.1 & 2.56 \\
\hline
\end{tabular}

Refer to Appendix Section 10 'Please rate on a scale of 1-5 (1: no pressure; 5 : intense pressure) how much you feel these external pressures (i.e. pressures someone else, e.g. surgeon, administrator or colleague puts on you) in your environment' for full statements.

airway surgery'; 'case started without preoperative examination as surgeon was waiting'; and 'patient on warfarin for mechanical valve given vitamin K 10 mg to bring down international normalised ratio in time for elective hip replacement surgery'.

Anaesthesiologists also cited examples of administrative external pressures related to insufficient hospital resources, including 'proceeding with cases without intensive care unit support when indicated' and 'having to run two operating theatres with one junior medical officer, one room with specialist and the other with junior doctor'. Examples provided for pressures to proceed despite fatigue included 'surgeon misleading anaesthesiologists regarding surgical time and plan so that cases are started, which go on longer than expected' and 'continuing way past hours when reasonable nursing and anaesthesia support are available for care of patients of ASA (American Society of Anesthesiologists physical status classification) 3 or more'.

\section{DISCUSSION}

The aim of our study was to replicate the survey conducted by Gaba et al in 1994 in California, United States, on a smaller scale in Singapore to evaluate the extent of production pressures among anaesthesiologists here. By adopting similar questions adapted to our local context, we found differing results, given the specific sociocultural environment and medical climate in the country. Respondents in our study worked at restructured hospitals, which are public tertiary hospitals, and anaesthesiologists were all salaried, as opposed to receiving fee-for-service payment as practised in some hospitals in California.

Despite the limitations of our study, as described below, our survey results indicated that production pressures are fairly prevalent in our medical environment. These include external pressures, such as surgeons pressurising anaesthesiologists to reduce turnover time and anaesthesiologists having to deal with limited resources (e.g. lack of sufficient intensive care unit beds), and internal pressures such as fatigue, feeling compelled to avoid delaying the start of surgery and a desire to avoid litigation.

Noteworthy findings of our survey included the prevalence of fatigue among anaesthesiologists and external pressures from surgeons. It was significant that close to half of the respondents felt that their elective list and call workloads were heavy and more than half attributed errors in clinical judgement to fatigue. All these were also significantly correlated with work hours, size of the operating theatre suite and number of cases attended to in a day. External pressures from surgeons were a key finding, as close to half of respondents reported having proceeded with cases against their inclination because surgeons or patients wanted to go ahead with the surgery, and even made changes to their practice in order to facilitate the start of surgery. The majority of respondents had to source for operating rooms to finish the surgeon's lists. Nearly half of our respondents had witnessed colleagues working under production pressure from surgeons to conduct anaesthesia in an unsafe manner. Fatigue was also an important element in our survey, as over half of our respondents attributed clinical errors to excess workload. Contrary to our findings, however, another study in 2003 from the United Kingdom ${ }^{(3)}$ found that anaesthesiologists do not fully appreciate the effects of fatigue on performance.

External pressures from surgeons or the administration are part of the operating theatre ecosystem. An article by Kirsner and Biddle in 2012 highlighted that errors in patient care were often the result of system design and process failures rather 
than inept providers. ${ }^{(4)}$ Clinicians also need to be aware that pressures on anaesthesiologists from other parties in the system may increase the risk of them making errors that could threaten patient safety. While nurturing patient safety culture, we need to be cautious about the interplay among various parties to optimise the efficiency of each. Previous studies have indicated that in perioperative patient care, production pressures often threaten the safety culture. ${ }^{(4)}$

Quality of care is defined by three components: structure, process and outcome..$^{(5)}$ Hence, the structure and process for recommendations to minimise production pressures were looked into. A newsletter from the Anaesthesia Patient Safety Foundation in 2001, ${ }^{(6)}$ which discussed areas where production pressure could reduce patient safety, listed areas such as pre-anaesthetic evaluation preparation of patients and reluctance to cancel or reschedule procedures. It was suggested that honest and realistic scheduling could help to improve patient safety. While it might be difficult for surgeons to accurately predict how long they are likely to take for a patient's surgery, it is equally essential that they be honest, accurate and ethical when scheduling procedures. ${ }^{(6)}$ Therefore, a possible recommendation that could help to alleviate undue external pressures on anaesthesiologists from surgeons would be to ensure appropriate emphasis on realistic scheduling of procedures within the ambit of hospital processes.

Furthermore, workload management could be optimised. A commentary in the Agency for Healthcare Research and Quality Patient Safety Network in 2007 reported a root cause analysis in which production pressures resulted in errors. It highlighted the importance of instituting staffing policies and procedures for handling changes in workloads by using a frontline approach to 'stop the presses' when production pressures threatened to compromise safety. ${ }^{(7)}$ It would be worth reviewing staffing policies and procedures to determine whether fatigue, as an internal factor for production pressure, could be minimised.

The present study was not without limitations. The number of responses to our survey was small, with only 70 anaesthesiologists responding to the questionnaire, although the total number of anaesthesiologists registered in Singapore was 432 according to Singapore Medical Council records. Despite efforts made to reach all registered anaesthesiologists, we were unable to ascertain whether all received an email invitation. The responses included in the final analysis were all from anaesthesiologists working at restructured hospitals, and therefore it is possible that our findings may not be representative of all anaesthesiologists in Singapore. As with surveys in general, there could be an inherent non-response bias, where anaesthesiologists who chose not to participate in our survey may have harboured differences in opinions and attitudes towards questions/statements in the survey. We are also aware of the sensitive nature of our questions, which may have deterred anaesthesiologists from participating (given the risk-averse nature of the profession), as they could be sensitive to suggestions or making admissions of having succumbed to production pressures and following unsafe practices. Fear associated with the medicolegal climate in Singapore could also deter anaesthesiologists from answering honestly in this regard. To this end, we used the online anonymous form to encourage respondents to be more frank when offering their honest opinion instead of hard copy survey forms. On the flip side, given the complete anonymity of the survey, it was difficult to verify if the demographics of our respondents were indeed reflective of our intended population.

In conclusion, production pressures exist in every system and can compromise patient safety. Our survey indicated the prevalence of such pressures among anaesthesiologists in Singapore and the implications for patient safety. Active steps should be taken to minimise such pressures so that patient safety can be maintained. This issue should be addressed directly to prevent adverse events and avoid patient harm.

\section{REFERENCES}

1. Gaba DM, Howard SK, Jump B. Production pressure in the work environment. California anesthesiologists' attitudes and experiences. Anesthesiology 1994; 81:488-500.

2. T J Hooper v. Northern Barge, 60 F.2d 737 Cir, 1932.

3. Flin R, Fletcher G, McGeorge P, Sutherland A, Patey R. Anaesthetists' attitudes to teamwork and safety. Anaesthesia 2003; 58:233-42.

4. Kirsner K, Biddle C. Production pressure and a culture of deviance in the insular operating room and the consequences of their 'normalisation': have we reached a Hooper moment? Int J Law Healthcare Ethics 2012; 8.

5. Posner KL, Freund PR. Patient safety and production pressure: scheduling and staff. Available at: http://www.apsf.org/newsletters/html/2001/spring/10staffing. htm. Accessed April 29, 2016.

6. Blitt CD. Patient safety and production pressure: private practice. Available at: http://www.apsf.org/newsletters/html/2001/spring/08privatepractice.htm. Accessed April 29, 2016.

7. Carayon P. Production pressures. In: Agency for Healthcare Research and Quality Patient Safety Network [online]. Available at: https://psnet.ahrq.gov/ webmm/case/150/. Accessed April 29, 2016. 


\section{APPENDIX}

\section{Sample of Survey Questionnaire}

1. Which hospital do you work in?

- Changi General Hospital

- Ng Teng Fong General Hospital

- KK Women's and Children's Hospital

- National University Hospital

- Singapore General Hospital

- Khoo Teck Puat Hospital

- Tan Tock Seng Hospital

- Others:

2. How many operating rooms are there in your operating theatre suite?

-1-3

$\cdot 11-20$

-4-6

• $>20$

- 7-10

3. What is the average number of cases that you do in a typical workday?
- $0-1$
- 5-7

- 2-4

$\cdot>7$

4. What is the percentage of outpatients in your list in a typical workday?

- $0 \%-25 \%$

- $26 \%-50 \%$

- $76 \%-100 \%$

5. How many hours do you work a week?
- 0-20
• 61-80
-21-40
- > 80

- 41-60

6 . How many years have you been in anaesthetic practice?
$\bullet<6$
$\cdot 16-20$
$\cdot 6-10$
$\cdot 21-25$
$\cdot 11-15$
$\cdot>25$

Please indicate your response from this scale which best corresponds to your response for each of the following statements (1: strongly disagree; 5 : strongly agree).

\begin{tabular}{|c|c|c|c|c|c|c|}
\hline 7. & On work environment and situation & & & & & \\
\hline 7.1 & My elective list workload is heavy. & 1 & 2 & 3 & 4 & 5 \\
\hline 7.2 & My call workload is heavy. & 1 & 2 & 3 & 4 & 5 \\
\hline 7.3 & I have made errors in clinical judgement that I attribute to excess workload during a case. & 1 & 2 & 3 & 4 & 5 \\
\hline 7.4 & There has never been a need or reason to cancel a case from the surgical schedule. & 1 & 2 & 3 & 4 & 5 \\
\hline 7.5 & If I cancel too many cases I may lose my job. & 1 & 2 & 3 & 4 & 5 \\
\hline 7.6 & There is administrative pressure to keep time between cases to a minimum. & 1 & 2 & 3 & 4 & 5 \\
\hline 7.7 & My pay is closely related to the number of cases I do. & 1 & 2 & 3 & 4 & 5 \\
\hline 7.8 & I feel fatigued at work. & 1 & 2 & 3 & 4 & 5 \\
\hline 7.9 & I have adequate time to evaluate my patients preoperatively. & 1 & 2 & 3 & 4 & 5 \\
\hline 7.10 & $\begin{array}{l}\text { I have cancelled a case because the patient has not undergone adequate preoperative } \\
\text { evaluation. }\end{array}$ & 1 & 2 & 3 & 4 & 5 \\
\hline 7.11 & I have refused to do a case because I thought the risks exceeded the likely benefits. & 1 & 2 & 3 & 4 & 5 \\
\hline 7.12 & $\begin{array}{l}\text { I have proceeded with cases that I would have cancelled except that the surgeon or patient } \\
\text { wanted to go ahead with the operation. }\end{array}$ & 1 & 2 & 3 & 4 & 5 \\
\hline
\end{tabular}


Please indicate your response from this scale which best corresponds to your response for each of the following statements (1: strongly disagree; 5: strongly agree).

\begin{tabular}{|c|c|c|c|c|c|c|}
\hline 8. & On work environment and situation (continued) & & & & & \\
\hline 8.1 & $\begin{array}{l}\text { I have proceeded with cases despite lack of appropriate support (e.g. technical equipment, } \\
\text { intensive care beds). }\end{array}$ & 1 & 2 & 3 & 4 & 5 \\
\hline 8.2 & I have refused to do a case because I thought the risks outweighed the likely benefits. & 1 & 2 & 3 & 4 & 5 \\
\hline 8.3 & I am concerned I might jeopardise my working relationship with the surgeon if I cancel a case. & 1 & 2 & 3 & 4 & 5 \\
\hline 8.4 & I have cancelled cases because I feared litigation if I proceeded. & 1 & 2 & 3 & 4 & 5 \\
\hline 8.5 & My opinions concerning medical care often differ from those of the surgeons. & 1 & 2 & 3 & 4 & 5 \\
\hline 8.6 & I enjoy a harmonious and effective working relationship with surgeons. & 1 & 2 & 3 & 4 & 5 \\
\hline 8.7 & $\begin{array}{l}\text { I have made changes to my practice in order to facilitate the start of surgery (e.g. choosing } \\
\text { general anaesthetic over regional technique even though regional anaesthetic would have } \\
\text { been my preferred technique). }\end{array}$ & 1 & 2 & 3 & 4 & 5 \\
\hline 8.8 & I have to source for operating rooms to finish the surgeon's list. & 1 & 2 & 3 & 4 & 5 \\
\hline 8.9 & I try to finish my list of cases quickly so that I can leave the hospital. & 1 & 2 & 3 & 4 & 5 \\
\hline 8.10 & I believe that production pressures have a negative impact on patient safety. & 1 & 2 & 3 & 4 & 5 \\
\hline 8.11 & $\begin{array}{l}\text { I have witnessed a colleague pressured to conduct anaesthesia in an unsafe manner given the } \\
\text { level of urgency for the situation. }\end{array}$ & 1 & 2 & 3 & 4 & 5 \\
\hline
\end{tabular}

If you answer 'agree' or 'strongly agree' to the last statement, please elaborate without any identifiers of name, date or location.

\begin{tabular}{|c|c|c|c|c|c|c|}
\hline \multirow{2}{*}{$\begin{array}{l}9 . \\
9.1\end{array}$} & \multicolumn{6}{|c|}{$\begin{array}{l}\text { Please rate from a scale of 1-5 (1: no pressure; } 5 \text { : intense pressure) how much you feel these internal pressures (i.e. } \\
\text { pressures that you put on yourself) in your environment. }\end{array}$} \\
\hline & Need to 'get along' with surgeons and maintain a harmonious relationship. & 1 & 2 & 3 & 4 & 5 \\
\hline 9.2 & Need to avoid delaying the start of surgery. & 1 & 2 & 3 & 4 & 5 \\
\hline 9.3 & Need to proceed under adverse conditions rather than be criticised or sidelined. & 1 & 2 & 3 & 4 & 5 \\
\hline 9.4 & $\begin{array}{l}\text { Need to avoid appearing overtly concerned about cases involving patients with complex } \\
\text { medical problems. }\end{array}$ & 1 & 2 & 3 & 4 & 5 \\
\hline 9.5 & Need to maximise number of cases done. & 1 & 2 & 3 & 4 & 5 \\
\hline 9.6 & Need to avoid litigation. & 1 & 2 & 3 & 4 & 5 \\
\hline
\end{tabular}

\begin{tabular}{|c|c|c|c|c|c|c|}
\hline \multirow{2}{*}{$\begin{array}{l}10 . \\
10.1\end{array}$} & \multicolumn{6}{|c|}{$\begin{array}{l}\text { Please rate from a scale of 1-5 (1: no pressure; 5: intense pressure) how much you feel these external pressures } \\
\text { (i.e. pressures someone else, e.g. surgeon, administrator, colleague, etc, puts on you) in your environment. }\end{array}$} \\
\hline & Proceeding with case rather than cancelling. & 1 & 2 & 3 & 4 & 5 \\
\hline 10.2 & Having your monitoring or anaesthetic technique interfered with. & 1 & 2 & 3 & 4 & 5 \\
\hline 10.3 & Having to hasten your anaesthetic preparation or induction. & 1 & 2 & 3 & 4 & 5 \\
\hline 10.4 & Need to reduce turnover time between cases. & 1 & 2 & 3 & 4 & 5 \\
\hline 10.5 & Being made to use inadequate equipment or less supplies than you would optimally use. & 1 & 2 & 3 & 4 & 5 \\
\hline 10.6 & Having to limit use of expensive drugs or equipment. & 1 & 2 & 3 & 4 & 5 \\
\hline
\end{tabular}

